\title{
科教融合建设一流本科专业
}

一厦门大学创建国家级一流化学专业的探索与实践

黎朝，温庭斌，吴伟泰，张延东，曹晓宇，朱亚先，吕釒唋

厦门大学化学化工学院, 福建厦门 361005

摘要: 厦门大学化学专业在九十余年的发展中积累了丰富的办学经验, 并拥有雄厚的教学与科学研究实力。本文从 人才培养模式、课程体系、实践教学平台、师资队伍建设、质量保障体系等方面, 介绍了该专业综合改革的主要举 措及成效, 并提出了下一步专业建设和改革的主要规划。

关键词: 一流本科专业; 科教融合; 专业建设

中图分类号: G64; O6

\section{Integration of Science and Education to Build a First-Class Undergraduate Major: Exploration and Practice of Developing National First-Class Chemistry Major at Xiamen University}

\author{
Zhao Li, Tingbin Wen, Weitai Wu, Yandong Zhang, Xiaoyu Cao, Yaxian Zhu, Xin Lü * \\ College of Chemistry and Chemical Engineering, Xiamen University, Xiamen 361005, Fujian Province, China.
}

\begin{abstract}
The chemistry major at Xiamen University has accumulated rich experience and strong teaching and research strength during more than 90 years of development. This paper reports the main measures and effects of the comprehensive reform of the major from the aspects of personnel training mode, curriculum system, practice teaching platform, teacher team construction and quality assurance system, and presents the roadmap for the future construction and reform of the chemistry major.
\end{abstract}

Key Words: First-class undergraduate major; Integration of science and education; Specialty construction

一流专业是一流人才培养的基本单元 ${ }^{[1]}$ 。为加快建设高水平本科教育, 提升人才培养质量, 教 育部于 2019年4月正式启动实施一流本科专业建设 “双万计划”。对标一流本科专业建设的文件精神, 厦门大学化学专业通过深入思考和研究近年来在专业综合改革方面的各项举措和成效, 形成了进一 步推进专业建设和改革的规划。

\section{1 科教融合, 凝练专业特色优势}

厦门大学化学专业始建于1921年, 历经刘树杞、傅鹰、卢嘉锡、蔡启瑞等为代表的几代数十位 化学名家的开拓耕耘, 已成为国内一流、国际具有重要影响的化学专业。拥有全国首批 “国家理科 基础科学研究和教学人才培养基地”、首批 “国家级实验教学示范中心”、首批 “国家级教学团队”、

收稿: 2020-10-06; 录用: 2020-11-16; 网络发表: 2020-12-11

“通讯作者, Email: xinlu@xmu.edu.cn

基金资助：国家基础科学人才培养基金项目(J1310024) 
首批 “第一类特色专业” ; 多次获得国家级教学成果奖, 2017年化学学科成功入选 “双一流” 建设 学科，2019年入选国家一流专业建设点。

经过长期的建设和发展, 厦门大学化学专业逐步形成了自己的办学优势和特色。一是重视本科 教学, 形成了院士、杰青、国家教学名师等为代表的优秀教授坚守本科基础课教学第一线的优良传 统; 二是聚焦国际前沿和国家重大战略需求, 注重学科交叉。经过化学专业长期孕育孵化, 国内率 先建立化学生物学、国际首创能源化学本科专业方向。拥有能源材料化学协同创新中心、固体表面 物理化学国家重点实验室等一批重大科研平台, 为培养本科生实践能力和创新意识提供了有力的保 障。三是坚持科教融合, 大力推进教学与科研协同育人, 促进科研与教学互动、科研与人才培养结 合, 形成了 “本-硕-博”一体化人才培养新模式。

\section{2 深化专业综合改革}

(1) 探索文化育人，实施 “浸润式”思政教育。

为深入落实立德树人的根本任务, 把思想政治工作贯穿教育教学全过程, 本专业积极探索文化 育人实施的有效途径。如, 通过开设 “先锋讲坛” “化院故事” “校友讲座” 等系列讲座, 引导学 生学习优良传统, 传承优秀文化, 培养学生的爱国情操和家国情怀。加强专业课 “课程思政” 建设, 充分挖掘学科、专业和课程内容中的德育内涵和育人元素, 将其 “基因式” 地融入到课程教学中, 激发学生的责任感、使命感与荣誉感, 激励学生不断提升专业素养。

(2) 制定了分层次人才培养方案和多元化课程体系。

随着新时代教育目标、教育理念和教育技术的深刻变化, 社会对人才培养提出了新的更高的要 求。人才培养模式已由专业对口向宽口径综合素质教育转变; 由注重知识传播向注重能力发展转变; 由注重共性教育向注重个性教育转变; 由注重学科系统性向注重学科交叉、融合转变 ${ }^{[2]}$ 。因此, 在制 定人才培养方案时我们提出了 “强化基础、面向前沿、因材施教、分类培养、注重能力、提高素质” 的基本指导方针。根据学生兴趣和未来发展需求, 分别设置了研究型人才、学科交叉型人才、创业 就业型人才等多元化培养体系。选择前两种培养方案的学生都有机会申请进入基础学科拔尖计划项 目学习, 并实施自主设计的个性化培养方案 ${ }^{[3]}$ 。

为保证多层次人才培养方案的实施, 构建了与之相适应的模块化、立体化课程体系, 形成了 “通 识类课程+学科通修类课程+专业方向性课程” 课程群。通识类课程和学科通修类课程对所有学生的 要求相同, 而不同培养模式的学生有其对应的不同模块的专业方向性课程群。培养方案和课程体系 立足于学生兴趣、能力、发展潜质的多元化, 为每位学生提供了各具特色的发展平台。

(3) 建设系列课程、打造精品课程群。

除了人文社科等全校性通识课程外, 本专业还为新生开设了 “新生研讨课” “创业基础” “实 验室安全与环保” 等通识类课程。聘请热心本科教学、学术水平高的教授以及业内成功的企业家校 友合作开课, 就学科知识图谱、学科的现状与前景、实验安全、行业创业理论知识、职业生涯规划、 自我设计与成才等方面进行介绍并展开研讨。目的是培养学生的社会责任感和对所学专业的热情, 引 导学生从入学开始就树立明确目标, 做好人生规划。

学科通修类课程是化学专业的主干课, 课程除了提供学生基本化学知识外, 更应注重帮助学生 构筑化学学科知识框架、发展化学学科思想、思维等高水平专业素质。以无机化学课程组为例, 他 们按照教育部高等学校化学类专业教学指导委员会制定的《化学类专业教学质量国家标准》和 “化 学类专业化学理论教学建议内容” 的要求, 对照培养目标和毕业要求, 遵循学科知识体系的逻辑顺 序, 注重基础知识与前沿研究的联系, 建设了富有厦门大学特色的无机化学课程群 ${ }^{[4]}$ 。在新教学理 念的带动下, 本专业进行了系列富有特色的精品课程建设, 形成了以 5 门国家精品课程(分析化学、 结构化学、无机化学、物理化学、综合化学实验)和 $8 门$ 省级精品课程(分析化学、结构化学、无机化 学、物理化学、综合化学实验、有机化学、仪器分析、基础化学实验二)、2门国家级精品资源共享课 
程(无机化学、结构化学)等为代表的专业基础课程群, 为学生提供了优质的教学平台。

专业方向性课程是专业特色的体现, 学生可根据自己的个性、兴趣和未来的职业规划, 在教师 指导下选择某一模块课程群内的课程并形成自己的专业方向。其中, 化学研究型专业模块课程强调 宽厚的化学基础理论和科研训练; 能源化学、化学生物学课程群旨在强化学生交叉学科的研究基础; 为拔尖计划学生专门设置的模块课程群则采用小班研讨教学, 强调自主学习和小组探究式学习。课 程群的建设应注重符合培养目标的要求, 支撑培养目标和毕业要求的达成。如, 为拔尖计划学生个 性化培养 “量身定制” 的 “强化实验” 课程群, 采用 “动态” 教材使教学内容 “活化”。实践 “先 做后教、以做定教” 的 “翻转课堂” 教学模式, 多渠道、全方位提高学生实验兴趣, 达到培养学生 创新意识和创新能力的目的 ${ }^{[5]}$ 。

(4) 形成了多层次的实践教学平台。

以培养学生的 “知识-能力-素质” 为主线, 在研究基础化学实验自身的教学与认知规律的基础 上, 对教学内容与课程体系进行整合, 形成了 “基础、综合、研究” 实验教学课程体系。实验选题 和内容每年均要求有一定比例的更新, 注重将教师的科研成果转化为学生实验内容。如 “四甲基乙 二胺碱式氯化铜配合物的制备及在酚催化偶联反应中的应用” “温度响应高分子微凝胶的水相制备 与表征” [6]等实验, 展现了厦门大学化学专业各二级学科的特色与优势, 也体现了教师的科研成果 对本科教学的反哺。

与课程教学过程相比, 科研过程具有面向未知世界、探索未知知识、解决真实问题等特点, 因 此参与科学研究更能使学生获得实践能力、批判思维和创新意识等方面的提升。我们以 “启发创新 意识、注重训练过程、提高综合素质” 为原则, 依托本专业科研团队的力量, 构建了初、中、高三 个层次循序渐进的科研训练平台 ${ }^{[7]}$, 引导、发现、培育学生的创新意识和实践能力。近三年本科生参 加课外科研训练项目 446 项, 参与发表科研论文 173 篇, 发明专利 1 项, 获省级及以上学业竞赛各类奖 项28项，参加社会实践项目52项。

(5) 围绕激发学生学习兴趣和潜能创新教学方法。

改革以知识传授为主的传统教学方式, 倡导以能力培养为导向、以问题探究为中心的 “教师引 导-学生参与” 的研究性教学。通过问题激发学生探究的兴趣, 在分析问题、解决问题的过程中引导 学生采取主动探究式学习, 从而培养学生的思维能力和实践能力。如 “无机化学” 采用线上与线下 相结合、翻转课堂等教学方式; “分析化学” 通过案例讨论、论文报告的方式; “有机化学” “物 理化学” “仪器分析” 通过课程论文方式培养学生查找文献、归纳、总结的能力; 与基础理论课相 配套的研讨课以及高年级专业方向性课程, 则采取小班研讨课的授课方式。教师课前将教学计划、 专题研讨学习要求、引导性阅读文献等发布给学生, 指导学生在课外阅读英文教材、文献, 现场 汇报PPT并开展讨论等。通过一系列活动培养了学生对前沿文献理解与批判性阅读能力、化学学科 思维与表达能力以及团队协作能力。研究性教学和探究式学习不但对学生提出了更高的要求, 也 对教师的教学组织能力、学科知识储备和科研能力提出了极高的要求。

积极推动网络课程建设, 探索现代信息技术与教育教学的深度融合。已实现全部课程在厦门大 学信息化教学平台网上开课, 每学期初对上网课程进行全面检查, 促进教师不断完善网络课程资源。 利用厦门大学 SPOC、中国大学MOOC、钉钉 ${ }^{[8,9]}$ 等平台, 实施线上线下相结合授课以及翻转课堂, 为 学生开展自主性、研究性学习提供了保障。

(6) 建立高层次的国际交流平台。

聘请国际双聘教授或名校教师主讲特色课程, 如邀请国际物理化学教学大师Peter Atkins、英国 皇家院士Philip Bartlett为代表的英国南安普敦教学团队进行物理化学国际暑期学校的授课。形成了 今日化学讲座、杰青论坛、诺贝尔获奖者讲座、卢嘉锡讲座、学术沙龙等系列活动, 为学生提供与 学术大师面对面的交流机会, 极大地开拓了学生的国际视野。

先后与英国剑桥大学、美国加州大学伯克利分校等多所国际一流大学签订联合培养协定或本科 
生交流合作计划; 设置了学术交流活动专项资助基金, 利用学校、学院与导师的学术资源, 支持学 生参加国内外学术活动、到国(境)外进行短期访学、学业竞赛、学术会议。近三年本科生共 65 人次获 资助完成了出境交流和学习。

\section{3 加强教学团队建设}

(1) 建设了一支高水平师资队伍。

形成了一支以院士、国家教学名师、杰青等高层次人才领衔, 年龄梯队合理、学科分布全面的 创新型本科基础课程教学队伍。他们以高水平的科研带动高质量的教学, 将科研的最新研究成果与 基础理论课程的内容相结合, 开拓了学生的学术视野, 启迪了学生的创新思维, 同时在思想、品德、 学风、人格方面成为学生学习的榜样。

(2) 建立了针对青年教师的 “引、培、推”培养机制。

关心和重视青年教师的成长, 制定了一系列制度落实对青年教师的教学传帮带。如 “新教师助 教制” “双/多主讲制” , 让新教师与教学经验丰富的教师协作教学, 为新教师的成长提供平台。举 办多种形式的活动, 如观摩 “本科教学示范岗” 优秀教师的现场教学、参加学校组织的青年教师教 学能力培训班以及院校、省市各级青年教师教学技能大赛, 帮助他们提高教学能力。

(3) 完善教学组织体系。

建立课程组制度, 将全部课程划入不同课程组, 进行归口管理。按照教学任务、质量保障、教 学研究与实践、教师发展、教学效果等指标对课程组工作进行年度考核, 确保常态化教学管理和提 升。在新冠疫情防控期间, 各课程组结合课程内容和特点, 采取灵活多样的方式开展线上教学 $[8,9]$, 取得了较好的教学效果。除了课程组内定期组织教学研讨、互相观摩听课之外, 还不定期举办课程 组群讨论会和课程组长交流会, 以解决课程群关联内容的层级递升优化, 推进整个课程体系的不断 改进。

通过多年的建设, 本专业形成了主要基础课程全部由院士、杰青、教学名师领衔主讲的教学传 统, 获评首批国家级教学团队、2018年省级本科教学团队、全国教育系统先进集体、省师德建设先 进集体，国家教学名师 2 人，省教学名师 4 人，多人获省高校青年教师竞赛奖。

\section{4 健全人才培养质量保障体系}

建立了以学生为中心、以管理和评价两大核心内容为引领的人才培养质量保障体系, 以确保培 养目标的实现和保持, 以及培养质量的达到和稳定。如图1所示, 形成了根据 “用人单位需求/往届毕 业生反馈 $\rightarrow$ 培养目标 $\rightarrow$ 毕业要求 $\rightarrow$ 课程体系” 顺序进行的自外向内、目标导向的外部评价机制, 以 及依据 “毕业要求 $\rightarrow$ 课程体系 $\rightarrow$ 课程质量 $\rightarrow$ 应届毕业生反馈” 顺序进行的自内向外、目标达成的内 部评价机制。内、外评价机制形成反馈闭环, 推动专业人才培养过程持续改进。

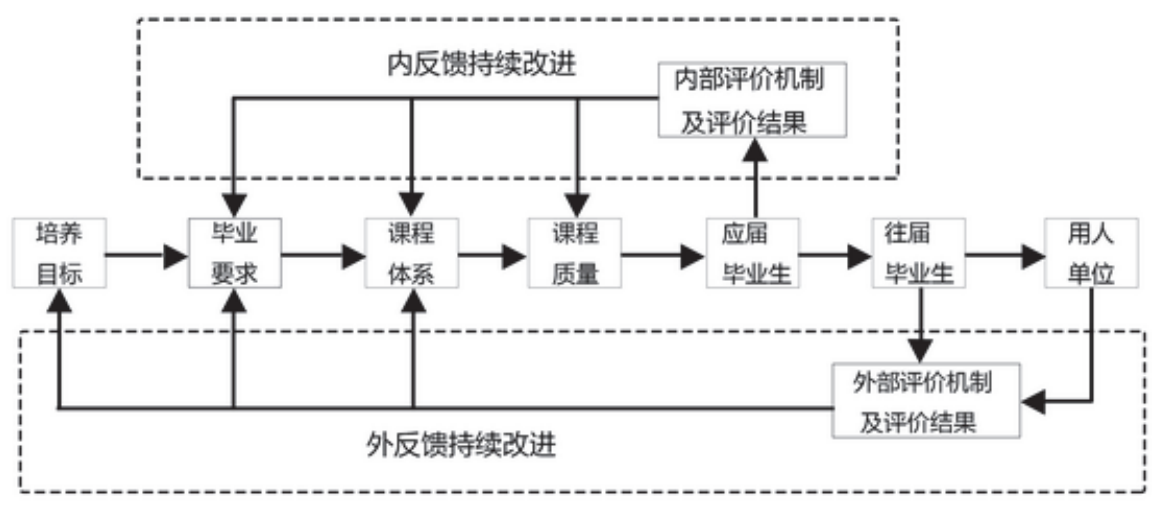

图1 推动专业人才培养过程持续改进的内、外反馈机制 
(1) 紧抓高质量培养过程。

建立了教学院长-系主任-课程组长-负责教授-主讲教师的课程逐级负责制。形成了多渠道的教 学质量反馈制度, 包括院系领导、督导组、课程组长以及课程组成员之间的课堂听课、期中教学检 查、“教授office time”、各类学生座谈会、课程组教学研讨会等, 及时形成评价反馈, 据此改进教学 方式、更新教学内容、完善教学计划。

(2) 注重毕业生与用人单位反馈。

建立了毕业生质量跟踪调查制度。在每届学生毕业离校前夕召开应届毕业班座谈会, 听取学生 对教学安排和课程质量等方面的意见和建议。选取出国、就业、国内升学等不同去向的毕业生及其 用人单位为代表, 通过多种方式获取毕业生对教学各环节的意见和建议、毕业生职业满意度和用人 单位对毕业生知识、素质和能力的评价等信息, 为教学质量持续改进提供参考。

(3) 构建专业动态调整机制。

以高层次专家指导本科专业教学持续改进。一方面充分发挥本专业院士、杰青、国家教学名师 等高端人才优势, 不断优化培养方案和课程体系; 另一方面, 邀请国际双聘教授和校外专家定期对 培养方案与科技、经济、社会持续发展需要的吻合度进行评估, 对人才培养模式进行多方位和持续 的改进。

\section{5 下一步专业建设和改革的推进规划}

(1) 持续建设素质过硬、潜心育人的一流师资队伍, 以教风建设引领学风建设。坚持引培结合原 则: 既重视吸引国际领军人才和杰出青年人才, 提升引进国外智力的层次, 更要加强对中青年教学 领军人才的发掘和培养。制定一系列教学激励政策鼓励教学研究: 如设立教学类重大奖项, 大力资 助和奖励教师出版教材、发表教学论文和参加教学技能竞赛等。

(2) 进一步优化人才培养结构, 探索创新人才培养模式。目前我们正积极探索建设荣誉学位体 系, 藉此增强学生学习的荣誉感和主动性, 激发学生在深度学习和科学研究上的最大潜能。同时继 续探索本-研一体化课程体系设置和课题贯通设计: 将部分研究生课程向本科生开放、将本科阶段课 题向研究生学习阶段延伸, 促进和深化本科生的科研训练, 进一步提高他们的创新研究能力。

(3) 按化学学科内在逻辑顺序和学生知识、素质、能力的形成规律, 重新梳理并优化课程体系。 成立了由科研能力强、学术水平高的教授组成的授课团队, 设计构筑 “中心科学实验班” 新课程体 系。新的课程体系按照物质结构 $\rightarrow$ 性能和反应规律 $\rightarrow$ 定量测量的认知顺序重构基础化学的理论课程, 强调 “重原理、强逻辑”, 强化学生的 “中心科学” 思维方式和交叉科学研究能力, 为学生提供更多 元化的后续发展方向并提高学生在跨学科领域创新的能力。同时该课程体系强化了化学核心课程基 础及难度, 将学科最新前沿动态引入教学, 提升课程的高阶性、创新性和挑战度。

(4) 主动发力, 推动公共课内涵升级。为使公共课程的内容与专业相结合, 进而提升学生兴趣与 教学效果, 我们在全校范围内倡导并推动了跨学院课程组的建设, 即派出本专业教师加入公共课的 课程组, 从本专业的视角, 以学生未来发展需求为导向推动公共课知识架构与教学模式的改革。如, 高等数学跨学院课程组对原来的高等数学课程进行了升级改造, 开设了 “自然科学中的数学 (一)、 (二)、 (三)” ; 在由物理学院开设的大学物理课程中增加了由化学专业教师讲授的 “振动与光学” 部 分内容。今后拟推动大学英语/大学语文课程内容与模式革新, 全面提升学生口头和文字表达与交流 的能力。

(5) 加强国际合作交流, 培养具有国际化视野的一流人才。将依托双一流平台建设, 进一步加强 与国际顶尖院校在科研和教学全方位的交流; 设立本科教学国际顾问委员会, 推进部分课程国际化 授课；以及构建包括跨课题组、国内外学术交流的多元化科训体系。

一流专业的建设并非一蹴而就, 而是师资队伍、培养理念、课程体系、实践平台等专业要素的 长期积累和持续优化。在高等教育由外延式向内涵式发展的进程中, 本专业将继续坚持以学生和学 
科建设为中心, 强化科教融合的办学理念, 构建国内外一流水平的化学专业, 培养具有国际竞争力 的高素质创新型化学人才。

\section{参 考 文 献}

[1] 吴岩. 中国大学教学, 2017, No. 11, 4 .

[2] “中国特色高等教育思想体系研究” 课题组. 中国高教研究, 2017, No. 4, 1 .

[3] 黎朝, 洪炜, 杨朝勇, 杨柳, 朱亚先. 大学化学, 2018, 35 (9), 1.

[4] 朱亚先, 匡勤, 汪骋, 黄荣彬, 杨士烑, 郑兰䔉. 大学化学, 2020,35 (8), 1.

[5] 任艳平, 吕银云, 郑啸, 林敏, 夏文生. 大学化学, 2019, 34 (10), 95.

[6] 张来英, 兰如月, 刘志红, 吴伟泰. 大学化学, 2021, 36 (2), 1912023.

[7] 朱亚先, 洪炜, 夏海平, 吕釒金, 谢兆雄, 杨朝勇, 曹晓宇, 郭祥群. 大学化学, 2019, 34 (10), 8.

[8] 张来英, 吴伟泰, 李海燕, 唐果. 大学化学, 2020, 35 (5), 33.

[9] 陈立，周金梅，胡菁，陈毅辉，林敏，阮永红，郑锦丽，魏爱琳. 大学化学, 2020,35 (5), 191. 